\title{
BMJ Open Environmental correlates of sedentary time and physical activity in preschool children living in a relatively rural setting in the Netherlands: a cross- sectional analysis of the GECKO Drenthe cohort
}

Congchao Lu, ${ }^{1,2,3}$ Guowei Huang, ${ }^{3,4}$ Eva Corpeleijn ${ }^{1}$

To cite: Lu C, Huang G, Corpeleijn E. Environmental correlates of sedentary time and physical activity in preschool children living in a relatively rural setting in the Netherlands: a crosssectional analysis of the GECKO Drenthe cohort. BMJ Open 2019;9:e027468. doi:10.1136/ bmjopen-2018-027468

- Prepublication history and additional material for this paper are available online. To view these files, please visit the journal online (http://dx.doi org/10.1136/bmjopen-2018027468).

Received 24 October 2018 Revised 3 April 2019 Accepted 3 April 2019
Check for updates

(C) Author(s) (or their employer(s)) 2019. Re-use permitted under CC BY. Published by BMJ.

For numbered affiliations see end of article.

Correspondence to

Dr Congchao Lu; c.lu@umcg.nl

\section{ABSTRACT}

Objectives This study examined the relationship between environmental correlates and children's sedentary time (ST), light physical activity (LPA) and moderate-to-vigorous physical activity (MVPA) in preschool children.

Design Cross-sectional study

Setting A birth cohort in Drenthe, a northern province and relatively rural area of the Netherlands.

Participants Valid data both for the ActiGraph and the questionnaire were obtained from 505 child-parent pairs.

Primary and secondary outcome measures ST, LPA and MVPA of children were objectively measured by ActiGraph accelerometry (minimum three wearing days, more than 10 hours/day). Environmental correlates were collected using a questionnaire reported by parents that included household characteristics, parental and children's PA behaviours and neighbourhood environment (eg, traffic safety, road network and presence of PA facilities). Potential correlates were identified using linear regression analysis, adjusted by age, gender, siblings, and maternal age and education level. Ordinary least square regression-based path analysis was used to estimate direct and indirect effects on activity outcomes in mediation models.

Results Linear regression analysis showed that 'parents taking children to play sports' was related to less ST, more LPA and MVPA; more outdoor play was also related to less ST and more LPA, but not MVPA. Parents who perceived more PA facilities in their neighbourhood showed more support for 'taking children to play sports', and this was associated with less ST or more MVPA compared with children living with less PA facilities in their neighbourhood. No evidence was found for a relation between traffic safety or road network with ST, LPA and MVPA.

Conclusions This study indicated that parental support and child outdoor play may influence children's daily PA patterns. Convenient neighbourhood PA facilities, such as parks and playgrounds, had an indirect effect through parental support associated with lower children's ST and higher MVPA, even in relatively rural areas.
Strengths and limitations of this study

The study was conducted in a relatively rural setting, a setting that has rarely been studied before.

- Sedentary time and physical activity were objectively measured in detail using an accelerometer device.

- The cohort was representative of the general population in terms of socioeconomic position and no strong bias of highly educated parents was present.

- The study is cross-sectional and therefore, the direction of causality cannot be inferred.

\section{INTRODUCTION}

The trend of physical inactivity is increasing rapidly in most societies around the world, equally in adults as well as in young people. ${ }^{1}$ Preschool years are a critical period of cognitive development and for the development of lifelong health habits, ${ }^{2}{ }^{3}$ for example, energy-balance-related behaviours, including physical activity (PA) and sedentary behaviours $(\mathrm{SB})$. The promotion of children's PA in their early years has become an important public health aim because it is associated with multiple health indicators. A systematic review has summarised that increased or higher PA was favourably associated with children's bone and skeletal health, motor skill development, psychosocial health, cognitive development and cardiometabolic health. ${ }^{4}$ It also becomes more and more evident, that the preschool years are a critical period for the development of childhood obesity. ${ }^{5}$ Unlike PA, SB are a distinct group of behaviours; high levels of SB can be accumulated even when children meet PA recommendations. Excessive SB may have adverse health consequences, for example, higher durations/frequencies of screen time and 
television viewing were associated with obesity risk in school-aged children and youth. ${ }^{6}$

From an ecological perspective, it is vital to focus not only on the individual determinants of PA but also on determinants in the social (eg, family) and physical (eg, neighbourhood) environments. ${ }^{7}$ The relationship between family, neighbourhood environments and children's PA levels is supported by multiple studies. For example, two reviews found consistent evidence that parental PA and support were positively associated with children's PA. ${ }^{89}$ Parental PA was associated with directly measured PA in young Dutch children. ${ }^{10}$ Besides, preschool children are highly dependent on their parents to create opportunities for diminishing their sedentary time (ST) ${ }^{11}$ In addition to parental influence, built environmental characteristics, such as road and sidewalk infrastructure and traffic safety, could affect children's PA, since these may influence children's mode of transportation or their opportunities for playing outside. ${ }^{12}$ A report demonstrated that each additional hour spent outdoors was associated with seven additional minutes of moderate-to-vigorous PA (MVPA) and 13 min less in ST among 7-14-year-old Canadian children per day. ${ }^{13}$ For preschool children, the correlation between outdoor play, objectively measured total PA and ST needs to be assessed, as outdoor time may be a good opportunity for children to be active. ${ }^{14}$ When investigating how more time can be spent in high-intensity activity, it is necessary to take into account that lifestyle behaviours do not exist in isolation. ${ }^{15}{ }^{16} \mathrm{~A}$ change in any behaviour must be done at the expense of one of the other behaviours, and each intensity of activity should be studied in relation to changes in other intensities, for example, ST, light PA (LPA) and MVPA. ${ }^{17}$

Parental perceptions of neighbourhood environmental characteristics may have a particular impact on children's PA level, since parents are most often the main decision-makers with regard to their child's activities. ${ }^{1819}$ Understanding the impact of the built environment on PA among young people is especially important for the design of effective interventions. First of all, intervention needs to be encouraged starting at an early age, since health benefits of sufficient PA during preschool years are increasingly being recognised. ${ }^{420}$ Second, the literature shows that interventions focused on behaviour modification that target individuals have limited effects on PA improvements, suggesting that supportive policies, along with social and physical environments, are required to support effective interventions. ${ }^{721}$ Third, changes in built environments and policies are expected to have long-term impact on most of the people living in those places, for example, by enhancing PA or reducing obesity. ${ }^{7}$ However, the number of studies investigating the correlates of family, built environment and objectively measured ST, LPA and MVPA in preschool children is limited..$^{22}$

Studies from developed countries have found a higher prevalence of obesity in rural areas. ${ }^{24}$ Compared with urban populations, people living in rural areas could be limited in their facilities for PA. ${ }^{25}$ At the same time, little is known about how these environmental factors are related to ST and total PA in rural populations, especially in young children.

The aim of this cross-sectional study was to examine whether neighbourhood characteristics are related to ST and total PA-divided into LPA and MVPA-objectively measured by accelerometry in preschool children from the Groningen Expert Centre for Kids with Obesity (GECKO) Drenthe birth cohort. The province of Drenthe is a relatively sparsely populated rural area with a population density of 183 per $\mathrm{km}^{2}$ in the year 2017 , where, unlike in many other parts of the Netherlands, the land use is mainly for agriculture. It is hypothesised that children living in a supportive neighbourhood environment at 45 months (eg, more PA facilities) will be more active compared with those living in a non-supportive environment, even in relatively rural areas. Furthermore, it will be explored how parental behaviours mediate the correlations between environmental characteristics and the child's daily activity patterns.

\section{METHODS GECKO Drenthe birth cohort}

Data were derived from the GECKO Drenthe birth cohort, which focuses on the development of overweight and obesity in children living in Drenthe, a northern province of the Netherlands. Details of the study have been reported elsewhere. ${ }^{26}$ All mothers of children born between April 2006 and April 2007, and living in Drenthe, were invited to participate during the third trimester of their pregnancy. At baseline, parents of 3875 children intended to participate in the study, but only 2874 actually ended up participating.

\section{Data collection}

Questionnaire data used in this study were collected by a series of questionnaires during the cohort follow-up. ${ }^{26}$ Child and family information including birth dates of family members, parental educational levels and ethnicity were collected at baseline. At follow-up, changes in number of siblings and family members were reported. Questionnaires for parents about environmental correlates were handed out during visits to the Well Baby Clinic when the child was 45 months of age. Children who had complete data on environmental correlates were selected as potential participants for this study. Flowchart of the participants used in this study is shown in figure 1 . When children were in their second year of preschool, around 5-6 years, trained Youth Health Care nurses measured height and weight as part of a regular health screening. Overweight and obesity of children were classified according to the age-specific and gender-specific cut-offs of Cole and Lobstein. ${ }^{27}$ Parental educational level, as an indicator of socioeconomic status in the Netherlands, was assessed as low/middle education or higher vocational education and university. ${ }^{28}$ 


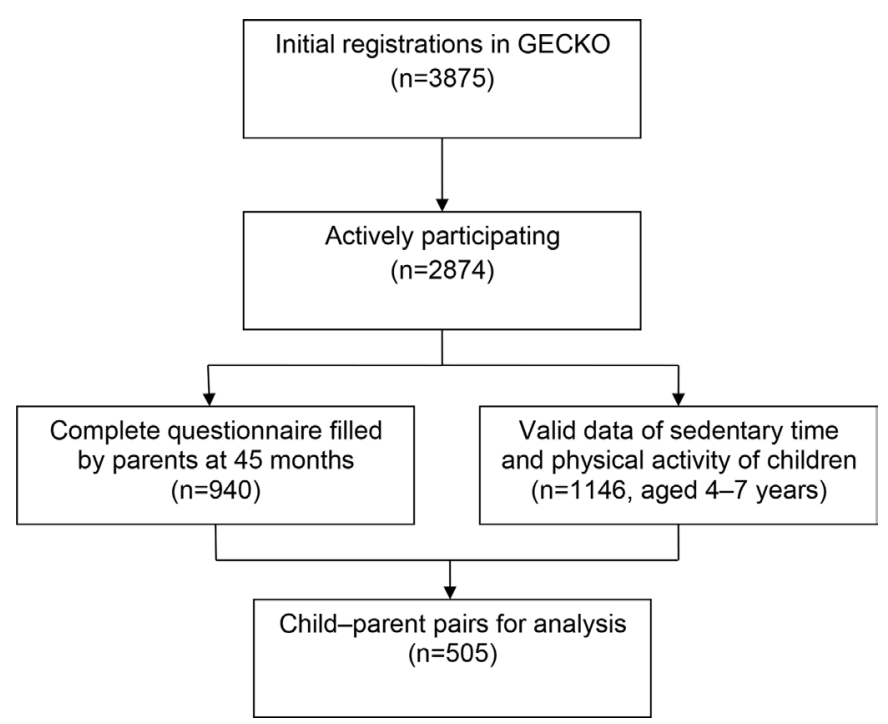

Figure 1 Flowchart of the participants in the GECKO study, the Netherlands.

\section{Environmental correlates}

Environmental correlates were assessed (2010-2011) using a Dutch questionnaire developed by Aarts et al, and the level of internal consistency of the scales was acceptable in this study. ${ }^{29}$ Parents/guardians reported their household characteristics (type and ownership of house, number of cars, and presence of garden and dog), their behaviours (taking child cycling/to play sports/accompanying going out) and their children's PA behaviours (outdoor play, regular cycling and going out by bicycle). The child's outdoor play was reported by parents in frequency and duration, and given in hours per week. Parents reported their perception of the traffic situation (Cronbach's $\alpha=0.708$ ) and road network (Cronbach's $\alpha=0.631$ ) in their neighbourhood in terms of two concepts. Each concept included five items, and each item had five options from 'totally disagree' to 'totally agree'. For a better understanding of the effect of environmental correlates, all items for each concept were combined into one dichotomised variable (favourable vs less favourable situation). For the presence of PA facilities (Cronbach's $\alpha=0.651$ ), parents reported their presence for six items (eg, park and playground) within a defined distance in their neighbourhood (eg, within a 5 min' walk or 20-30 min). A distance index was made combining the six places together; a higher score meant all places were close to their home.

\section{ST and PA}

ST, LPA and MVPA in children were assessed using ActiGraph GT3X (ActiGraph, Pensacola, FL, USA) accelerom-

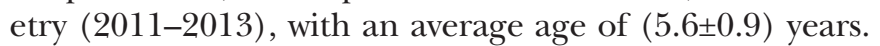
Details of the measurements have been reported elsewhere. ${ }^{30}$ The ActiGraph has been shown to be a reliable and valid device to measure PA volume and intensity in preschool children. ${ }^{31}$ Parents were instructed to have their child wear the ActiGraph on the iliac crest of the right hip with an elastic belt for four consecutive days-with at
Table 1 Characteristics of the study population in the GECKO study, the Netherlands

\begin{tabular}{|c|c|}
\hline Characteristics $(n=505)$ & Total \\
\hline $\begin{array}{l}\text { Age of the child at questionnaire } \\
\text { interview (years), mean (SD) }\end{array}$ & $3.9(0.2)$ \\
\hline $\begin{array}{l}\text { Age of the child at physical activity } \\
\text { measurement (years), mean (SD) }\end{array}$ & $5.6(0.9)$ \\
\hline Maternal age (years), mean (SD) & $37.0(4.2)$ \\
\hline Paternal age (years), mean (SD) & $39.6(4.6)$ \\
\hline Body mass index, median (25th; 75th) & $15.7(15.0 ; 16.6)$ \\
\hline Obesity and overweight, $\mathrm{n}(\%)^{*}$ & $53(12.1)$ \\
\hline Normal weight/underweight, n (\%) & $386(87.9)$ \\
\hline \multicolumn{2}{|l|}{ Ethnicity, n (\%) } \\
\hline Dutch & $472(94.8)$ \\
\hline Non-Dutch & $26(5.2)$ \\
\hline \multicolumn{2}{|l|}{ Maternal education, n (\%) } \\
\hline Low/middle & $290(57.4)$ \\
\hline High & $215(42.6)$ \\
\hline \multicolumn{2}{|l|}{ Paternal education, $\mathrm{n}(\%)$} \\
\hline Low/middle & $305(60.4)$ \\
\hline High & $200(39.6)$ \\
\hline \multicolumn{2}{|l|}{ Having siblings, $\mathrm{n}(\%)$} \\
\hline Yes & $450(89.1)$ \\
\hline No & 55 (10.9) \\
\hline \multicolumn{2}{|l|}{ Single-parent family structure, $\mathrm{n}(\%)$} \\
\hline Yes & $48(9.5)$ \\
\hline No & $457(90.5)$ \\
\hline \multicolumn{2}{|l|}{ Physical activity patterns (min/day) } \\
\hline Sedentary time, mean (SD) & $372(54)$ \\
\hline Light physical activity, mean (SD) & $266(39)$ \\
\hline $\begin{array}{l}\text { Moderate and vigorous physical } \\
\text { activity, median (25th; } 75 \text { th) }\end{array}$ & $61(48 ; 80)$ \\
\hline
\end{tabular}

${ }^{*}$ Overweight based on Z-scores Cole 5 years, $\mathrm{n}=66$ missing.

least one of the days being during the weekend-for all waking hours, except when bathing or swimming. Data were collected using a frequency of $30 \mathrm{~Hz}$. Collected data were analysed in $15 \mathrm{~s}$ epochs. The accelerometer wear and non-wear time were classified as recommended by Choi et al, and cut-off points for calculating time spend in ST, LPA and MVPA were recommended by Butte et al. All children with wear time $\geq 14$ hours /day were checked manually for sleeping time. ${ }^{32}{ }^{33}$ For valid measurements in this study, wear time had to be at least 10 hours/day for at least 3 days, regardless of whether these were week or weekend days. Time spent for ST, LPA and MVPA were calculated as means over at least three wearing days. ST, LPA and MVPA together add up to the total activity of that day.

\section{Statistical analysis}

Continuous variables were presented as means with SDs, or, if data were skewed, as the median with 25 th-75th 


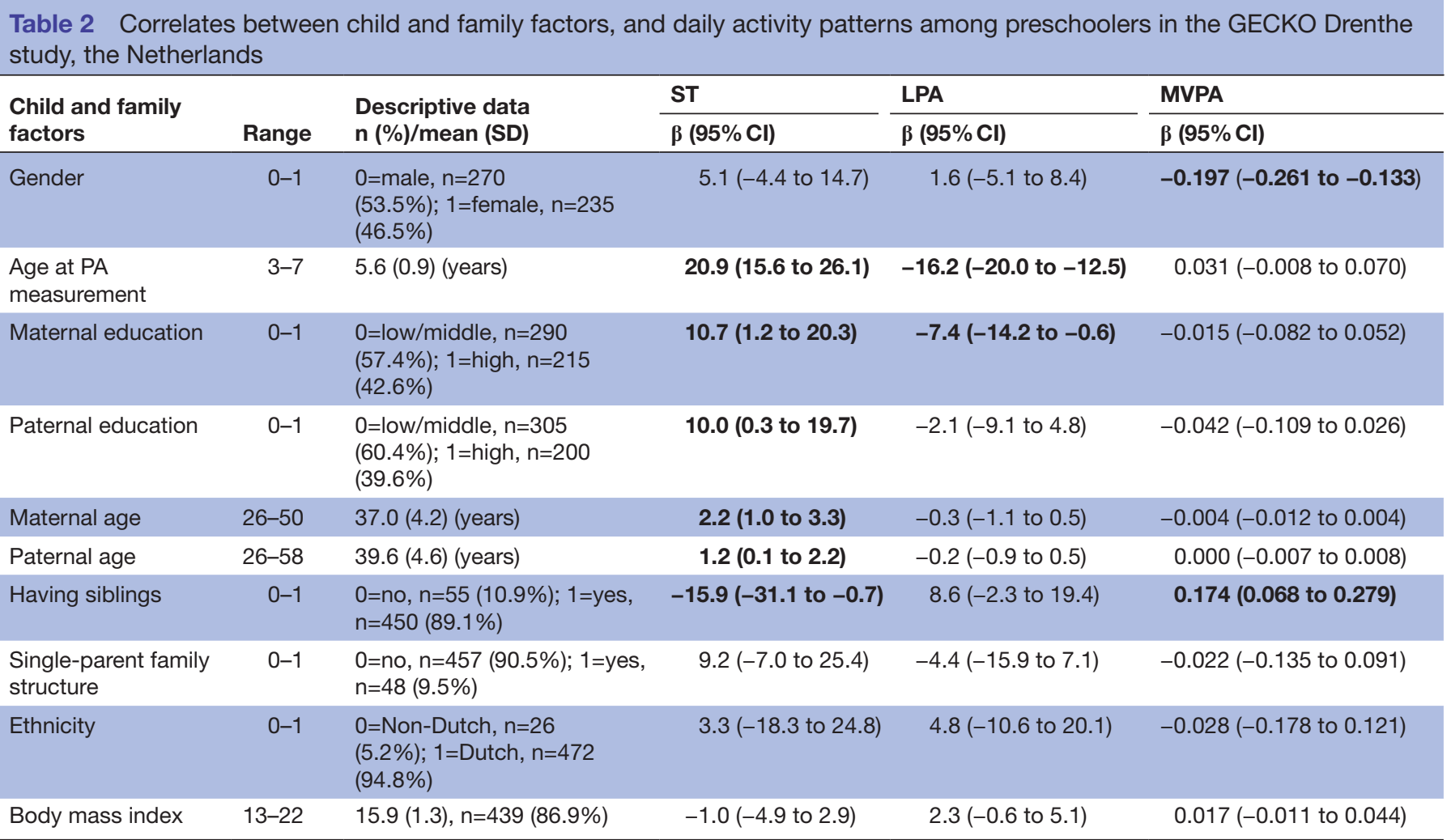

For binary variables, the group with zero was defined as the reference group.

Bold: $p$ value $<0.05$.

In, natural logarithm; LPA, light physical activity, means by minutes per day; MVPA, moderate-to-vigorous physical activity, In transformation of means by minutes per day; PA, physical activity; ST, sedentary time, means by minutes per day.

percentile. Categorical variables were presented as rates in number and percentages. Dependent skewed variables were natural logarithm (ln)-transformed for linear regression. To examine the differences of characteristics between children with ActiGraph data included in the analyses to children lacking questionnaire data, t-test was used for normally distributed continuous variables and Mann-Whitney U test was used for non-normal distributed continuous variables. Differences in categorical variables were tested by $\chi^{2}$ test. To determine the relationships between potential correlates and outcomes, linear regression analysis adjusted for child and family factors was used. Then all significant variables (normal distribution) and outcomes were checked by Pearson correlation, or Spearman correlation was used if data were skewed. Ordinary least square regression-based path analysis was used to estimate direct and indirect effects on ST and MVPA in mediation models with the PROCESS macro for SPSS (Hayes, 2018, http://www.afhayes.com/). The independent variable was 'number of PA facilities' in the model, with 'parents taking children to play sports' as mediator, since 'parents taking children to play sports' was correlated with both 'number of PA facilities' and outcomes of ST/MVPA. No mediation analysis was used for LPA, since it was not correlated with "number of PA facilities'. Besides, age, gender, having siblings, maternal age, education level and child outdoor play were all included as covariates in the mediation models. For the indirect effects, 10000 bootstrap samples were used for bias-corrected bootstrap CIs, and a statistically significant indirect effect existed if the CI did not include zero. IBM SPSS Statistics V.22 for Windows was used for this study, with test level $\alpha=0.05$, and analyses were conducted in 2017.

\section{Patient and public involvement}

There was no patient involvement in the development of the research question or the selection of outcome measures. Results of this study are disseminated in a newsletter and on the website.

\section{RESULTS}

A total of 940 children, aged $(3.9 \pm 0.2)$ years, had valid data on parents' perception of neighbourhood environmental correlates, while 1146 children, aged 4-7 years, had valid ActiGraph data. Combined, 505 child-parent pairs had data both for the ActiGraph and the questionnaire, and were available for analysis (figure 1). Missing data for neighbourhood characteristics were mainly attributable to logistical and organisational problems, since the Well Baby Clinics services' paper files were digitised during the data collection period (2010-2011) in 
Drenthe. The characteristics of the study population are presented in table 1.

When comparing children with ActiGraph data included in the analyses to children lacking questionnaire data $(n=641)$, the ST, LPA and MVPA were comparable $(p>0.05)$. Meanwhile, gender distribution was comparable between this study group $(n=505$, boys $=53.5 \%)$ and the total population of GECKO $(n=2874$, boys $=50.3 \%$, $\mathrm{p}>0.05$ ). However, the children included in this study showed a higher level of maternal education $(42.6 \%)$ compared with the total population $(34.9 \%, \mathrm{p}<0.05)$. This study showed that higher-level education mothers were more likely to finish both the questionnaire and the measurement of children's daily activities. Missing data of this study group was not imputed, due to a small proportion that was missing (less than $3 \%$ ).

The associations of child and family factors with children's ST, LPA and MVPA by linear regression analysis are given in table 2. Girls showed less MVPA than boys. Children's age and higher maternal educational level were positively associated with ST and negatively associated with LPA. Higher paternal educational level and older parents determine children with higher ST. Children with siblings showed lower ST and higher MVPA. Single-parent household, ethnicity and body mass index were not associated with outcomes. Thus, potential environmental correlates were analysed by adjusting for children's gender and age, maternal age and educational levels, and having siblings. Paternal age and education were not included due to collinearity with maternal factors $(\mathrm{r}=0.656, \mathrm{p}=0.000$; $\mathrm{r}=0.343, \mathrm{p}=0.000$, respectively).

Environmental correlates of children's ST, LPA and MVPA by linear regression analysis are presented in table 3. This study indicated that none of the household characteristics was related to children's ST, LPA or MVPA. From parents' perception of neighbourhood environmental correlates, no evidence was found for traffic safety or road network in relation to these outcomes. The results showed that children spent less time on ST if parents reported more PA facilities within 5 min' walking distance $(\beta=-3.6)$, and showed more MVPA if parents reported more facilities within 30 min' walking distance $(\beta=0.027)$ or more facilities close to their house as summed together (distance index) $(\beta=0.007)$. For parents' behaviours, taking children to play sports was inversely related to children's ST $(\beta=-7.9)$, and positively to LPA $(\beta=5.3)$ and MVPA ( $\beta=0.068)$. For children's PA behaviours, more outdoor play was related to lower ST $(\beta=-1.0)$ and higher LPA $(\beta=0.8)$, but not MVPA.

Correlations between significant variables and outcomes are presented in table 4 . This study indicated that 'parent taking child to play sports' correlated with all variables in the table except for 'child's outdoor play'. 'Facilities within 5 min' walk' negatively correlated with children's ST $(r=-0.101, p<0.05)$, 'facilities within 30 min' walk' positively correlated with children's MVPA $(r=0.105, \mathrm{p}<0.05)$ and 'distance index' correlated with both ST (negatively, $\mathrm{r}=-0.090, \mathrm{p}<0.05$ ) and MVPA (positively, $\mathrm{r}=0.094, \mathrm{p}<0.05$ ).
Path coefficient models were used for investigating the role of parental support acting as mediator in the associations between numbers of PA facilities and ST/MVPA. As shown in figure 2, for both of the two path models, the indirect effect of parental support between facilities and children's ST/MVPA was significant (path coefficients $[95 \% \mathrm{CI}]$ for ST: $-0.4[-1.1$ to -0.0$]$ and path coefficients [95\% CI] for MVPA [ln]: 0.004 [0.001 to 0.009]). If parents perceived more PA facilities in their neighbourhood, they showed more support for 'taking children to play sports', and this was associated with less ST or more MVPA compared with children living with less PA facilities in their neighbourhood. The indirect effect of "parent taking child to play sports' was also significant between 'distance index' and children's ST/MVPA; this data is shown in online appendix figure $\mathrm{A}$.

\section{DISCUSSION}

This study examined how neighbourhood characteristics are associated with daily activity patterns in preschoolers. The results showed that parental support for participating in sports was related to less ST, more LPA and MVPA. Furthermore, parental support also acted as mediator in the associations between numbers of PA facilities and children's activities, for example, lower ST and more MVPA. Moreover, children who spent more time in outdoor play were also less sedentary and more active in LPA, though not in MVPA.

The accessibility of recreational PA facilities would seem to have an influence on daily activity patterns among preschool children, since these facilities are the most common places for children to be active. A previous review found a significant positive association between the proximity of parks and playgrounds to the home and children's PA. ${ }^{34}$ But much of the research on the correlation of built environment characteristics and PA took place in urban areas. ${ }^{35}$ This study indicated that improving recreation facilities may be a useful strategy in developing an active neighbourhood, even in rural areas. Moreover, for PA promotion in young children, parental help is important. Parents were able to influence their children's participation in PA through a variety of mechanisms, for example, direct parental display of PA; higher maternal PA was related to more preschool children's MVPA in another study of the GECKO cohort. ${ }^{10}$ Parental influence is most definitely important for the promotion of PA, especially when parents give their children the opportunity to be more active, for example, by encouraging playing outside or playing more sports. ${ }^{12} 36$ Furthermore, from the point of view of social cognitive theory, involvement of both individual factors and environmental components are essential to affect changes in health behaviour. ${ }^{37}$ Thus, families living in a supportive neighbourhood may have more opportunities to be physically active, and active parents may be more aware of available facilities in their neighbourhoods; as a result, they are more likely to make use of these facilities for 
Table 3 Correlates between environmental characteristics and daily activity patterns among preschoolers in the GECKO Drenthe study, the Netherlands

\begin{tabular}{|c|c|c|c|c|c|}
\hline & & Descriptive data & ST & LPA & MVPA \\
\hline Variable & Range & n (\%)/median (25th; 75th) & $\beta(95 \% \mathrm{Cl})$ & $\beta(95 \% \mathrm{Cl})$ & $\beta(95 \% \mathrm{Cl})$ \\
\hline \multicolumn{6}{|l|}{ Household characteristics } \\
\hline Cars & $0-1$ & $\begin{array}{l}0=\text { one car, } \mathrm{n}=184 \\
(36.6 \%) ; 1=\text { more than two cars, } \\
\mathrm{n}=319(63.4 \%)\end{array}$ & $-6.2(-15.6$ to 3.2$)$ & $5.5(-1.1$ to 12.2$)$ & $0.000(-0.067$ to 0.068$)$ \\
\hline $\begin{array}{l}\text { Type of house: detached } \\
\text { house }\end{array}$ & $0-1$ & $\begin{array}{l}0=\text { others, } n=322 \\
(63.9 \%) ; 1=\text { detached house, } n=182 \\
(36.1 \%)\end{array}$ & $1.6(-8.0$ to 11.2$)$ & $-2.2(-9.0$ to 4.6$)$ & $0.012(-0.056$ to 0.081$)$ \\
\hline $\begin{array}{l}\text { Type of house: semidetached } \\
\text { house }\end{array}$ & $0-1$ & $\begin{array}{l}0=\text { others, } n=324 \\
(64.3 \%) ; 1=\text { semidetached house, } \\
n=180(35.7 \%)\end{array}$ & $-0.1(-9.4$ to 9.2$)$ & $-2.1(-8.8$ to 4.5$)$ & $-0.002(-0.068$ to 0.065$)$ \\
\hline Type of house: row house & $0-1$ & $\begin{array}{l}0=\text { others, } n=432 \\
(85.7 \%) ; 1=\text { row house, } n=72(14.3 \%)\end{array}$ & $4.0(-8.9$ to 16.9$)$ & $2.8(-6.3$ to 11.9$)$ & $-0.027(-0.119$ to 0.065$)$ \\
\hline House ownership & $0-1$ & $\begin{array}{l}0=\text { privately owned, } n=460 \\
(93.5 \%) ; 1=\text { rental house, } n=32(6.5 \%)\end{array}$ & $1.0(-17.4$ to 19.4$)$ & $-3.5(-16.5$ to 9.5$)$ & $0.073(-0.059$ to 0.206$)$ \\
\hline Dog in the house & $0-1$ & $\begin{array}{l}0=n o, n=404(80.5 \%) ; 1=y e s, n=98 \\
(19.5 \%)\end{array}$ & $-3.7(-15.0$ to 7.6$)$ & $2.3(-5.7$ to 10.4$)$ & $0.006(-0.076$ to 0.087$)$ \\
\hline Garden & $0-1$ & $\begin{array}{l}0=n o, n=2(0.4 \%) ; 1=y e s, n=503 \\
(99.6 \%)\end{array}$ & - & - & - \\
\hline \multicolumn{6}{|c|}{ Parents' perception of neighbourhood environment } \\
\hline Traffic safety & $0-1$ & $\begin{array}{l}0=\text { less favourable, } n=175 \\
(35.1 \%) ; 1=\text { favourable, } n=324 \\
(64.9 \%)\end{array}$ & $4.0(-5.4$ to 13.4$)$ & $1.1(-5.6$ to 7.8$)$ & $-0.023(-0.091$ to 0.044$)$ \\
\hline Road network & $0-1$ & $\begin{array}{l}0=\text { less favourable, } n=161 \\
(32.3 \%) ; 1=\text { favourable, } n=337 \\
(67.7 \%)\end{array}$ & $0.2(-9.4$ to 9.9$)$ & $0.6(-6.3$ to 7.4$)$ & $-0.005(-0.074$ to 0.064$)$ \\
\hline Number of PA facilities & & $\mathrm{n}=505(100 \%)$ & & & \\
\hline Within 5 min walk & $0-6$ & $2(1 ; 3)$ & $-3.6(-6.7$ to -0.5$)$ & $2.0(-0.2$ to 4.2$)$ & $0.022(-0.001$ to 0.044$)$ \\
\hline Within 10 min walk & $0-6$ & $3(2 ; 4)$ & $-1.5(-4.5$ to 1.4$)$ & $-0.1(-2.2$ to 2.0$)$ & $0.015(-0.006$ to 0.036$)$ \\
\hline Within 20 min walk & $0-6$ & $4(3 ; 5)$ & $-1.9(-4.9$ to 1.1$)$ & $0.5(-1.6$ to 2.7$)$ & $0.014(-0.007$ to 0.036$)$ \\
\hline Within 30 min walk & $0-6$ & $5(4 ; 6)$ & $-2.0(-5.2$ to 1.3$)$ & $0.7(-1.6$ to 3.0$)$ & $0.027(0.004$ to 0.050$)$ \\
\hline$\geq 30$ min walk & $0-6$ & $1(0 ; 2)$ & $1.4(-1.8$ to 4.7$)$ & $-0.4(-2.7$ to 1.9$)$ & $-0.021(-0.044$ to 0.002$)$ \\
\hline Distance index* & $6-30$ & $20(17 ; 24)$ & $-0.8(-1.6$ to 0.1$)$ & $0.3(-0.3$ to 0.9$)$ & $0.007(0.001$ to 0.013$)$ \\
\hline \multicolumn{6}{|l|}{ Parents'/guardians' behaviours } \\
\hline Taking child cycling & $0-2$ & $\begin{array}{l}0=0-2 \text { days/week, } n=177 \\
(35.3 \%) ; 1=3-4 \text { days/week, } n=174 \\
(34.7 \%) ; 2=5-7 \text { days/week, } n=150 \\
(29.9 \%)\end{array}$ & $1.2(-4.4$ to 6.7$)$ & $-1.1(-5.0$ to 2.9$)$ & $-0.003(-0.042$ to 0.037$)$ \\
\hline Taking child to play sports & $0-2$ & $\begin{array}{l}0=0 \text { day/week, } n=296 \\
(59.6 \%) ; 1=1 \text { day/week, } n=129 \\
(26.0 \%) ; 2=2 \text { or more days/week, } \\
n=72(14.5 \%)\end{array}$ & $-7.9(-14.0$ to -1.8$)$ & $5.3(1.0$ to 9.6$)$ & $0.068(0.024$ to 0.111$)$ \\
\hline Accompanying going out & $0-2$ & $\begin{array}{l}0=0-2 \text { days/week, } n=160 \\
(31.9 \%) ; 1=3-4 \text { days/week, } n=153 \\
(30.5 \%) ; 2=5-7 \text { days/week, } n=188 \\
(37.5 \%)\end{array}$ & $1.2(-4.2$ to 6.6$)$ & $1.4(-2.4$ to 5.2$)$ & $-0.008(-0.047$ to 0.030$)$ \\
\hline \multicolumn{6}{|l|}{ Children's PA behaviours } \\
\hline Outdoor play & $0-17.5$ & $\begin{array}{l}9(5.3 ; 12.5) \text { (hours/week), } \mathrm{n}=503 \\
(99.6 \%)\end{array}$ & $-1.0(-1.9$ to -0.1$)$ & $0.8(0.1$ to 1.4$)$ & $0.004(-0.002$ to 0.011$)$ \\
\hline Regular cycling & $0-1$ & $\begin{array}{l}0=n o, n=161(32.3 \%) ; 1=y e s, n=337 \\
(67.7 \%)\end{array}$ & $-7.8(-17.4$ to 1.8$)$ & $0.4(-6.4$ to 7.3$)$ & $0.024(-0.044$ to 0.093$)$ \\
\hline Going out by bicycle & $0-2$ & $\begin{array}{l}0=\text { never, } n=216 \\
(42.8 \%) ; 1=\text { sometimes, } n=198 \\
(39.2 \%) ; 2=\text { often, } n=91(18.0 \%)\end{array}$ & $-1.3(-7.3$ to 4.8$)$ & $1.5(-2.8$ to 5.8$)$ & $0.031(-0.012$ to 0.074$)$ \\
\hline
\end{tabular}

All correlates were adjusted for children's gender and age, maternal age and educational levels, and siblings in the family. For binary variables, the group with zero was defined as the reference group.

Bold: $p$ value $<0.05$.

*Distance index was synthesised by the six PA facilities in the neighbourhood; higher score meant these places were close to home.

In, natural logarithm; LPA, light physical activity, means by minutes per day; MVPA, moderate-to-vigorous physical activity, In transformation of means by minutes per day; PA, physical activity; ST, sedentary time, means by minutes per day. 
Table 4 Correlation between variables and outcomes in the study

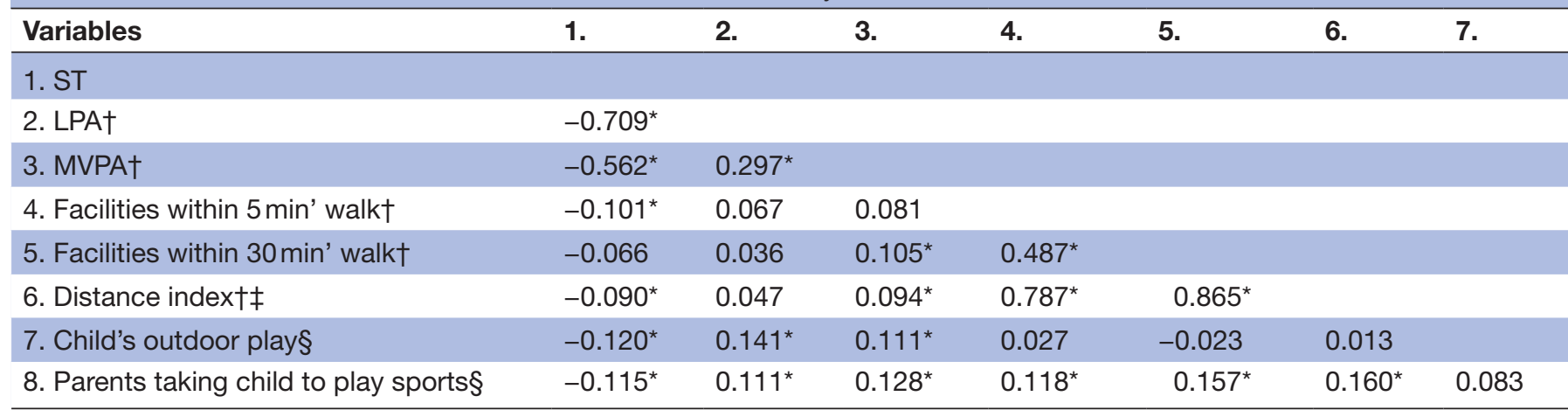

${ }^{*} \mathrm{P}<0.05$.

†Pearson correlation was used.

fDistance index was synthesised by the six PA facilities in the neighbourhood; higher score meant these places were close to home. $\S$ Spearman correlation was used.

In, natural logarithm; LPA, light physical activity, means by minutes per day; MVPA, moderate-to-vigorous physical activity, In transformation of means by minutes per day; ST, sedentary time, means by minutes per day.

themselves and their children. Parental support should be taken into consideration, when developing active neighbourhood-targeted interventions.

In this study, traffic safety and road network were not found to be related to children's LPA or MVPA in Drenthe, the Netherlands. Thought a study reported that parental traffic safety perceptions were positively associated with MVPA in German preschoolers on weekend days. ${ }^{22}$ Some studies found that traffic safety was an important characteristic associated with parents' reported outdoor play and children cycling. ${ }^{28}{ }^{38}$ In this study, both a favourable situation in terms of traffic safety $(\rho=0.144, p=0.001)$ and road network ( $\rho=0.090, p=0.045$ ) were positively correlated to a higher frequency of child cycling when they went outside. Despite this, it seems that traffic safety and road network did not contribute substantially to daily LPA or MVPA in preschool children in Drenthe. However, it might be expected to be associated with transport/leisure-time
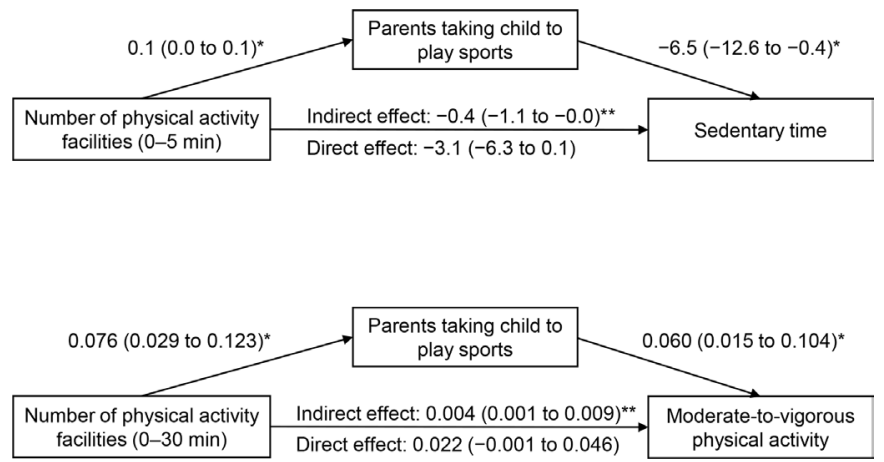

Figure 2 Direct and indirect pathways of environmental characteristics on sedentary time and moderate-to-vigorous physical activity among preschoolers in the GECKO study, the Netherlands. Ordinary least square regression-based path analysis was used for direct and indirect effects, unstandardised $\beta$ was given in the model, adjusted for child age and gender, maternal age and education, having siblings and child outdoor play. ${ }^{*} \mathrm{P}<0.05$. ${ }^{*} 95 \% \mathrm{Cl}$ does not encompass zero.
PA later in school life, for example, active commuting to school. ${ }^{3839}$

The health benefits of outdoor activity, assuming that this leads to higher total PA, have been emphasised by several researchers in terms of reducing myopia, developing motor skills, and along with improving social skills, since children learn how to deal with each other. ${ }^{40}$ More and more evidence indicates that unstructured outdoor play in 3-year to 12-year olds has declined over time and that it has nowadays been replaced by more time using electronic media indoors. ${ }^{41}{ }^{42}$ This study indicated that more outdoor play would not contribute to the MVPA guideline but would probably contribute to the SB guideline. For example, we found that every additional hour spent outdoors per day was associated with 5.6 additional minutes of LPA and 7 min less of ST on an average day among the Dutch preschoolers in this study. For a global public health policy aimed at lower SB and at increasing LPA, encouraging outdoor play might prove to be an effective strategy in children, since outdoor play is a cheap and natural way for children to be physically active. ${ }^{43}$

An important strength of this study was the good representativeness of the study population with regard to socioeconomic position and a large sample size compared with similar studies. ${ }^{45}$ This study examined correlates of objectively measured ST, LPA and MVPA separately, which provided full understanding of environmental influences on children's daily behaviours. However, due to incomplete data, a considerable number of cases could not be included in the analysis. The selection bias was small, with a slight bias towards higher-educated families but still more representative than other cohorts. An important methodological concern is that the evidence is based primarily on a cross-sectional study; therefore, children's behaviour before and after environmental changes were not evaluated. The measurements of ST, LPA and MVPA that after data collection of household characteristics were lasting for $(1.7 \pm 0.9)$ years, and during this 
period, there could be some small changes of parents' reported characteristics. Thus, our hypotheses need to be tested further, and longitudinal study designs would make causality inferences between the predictors and activity outcomes more feasible to determine.

\section{CONCLUSIONS}

In conclusion, this study showed that parents' perception of neighbourhood PA facilities relates to a lower ST and higher MVPA in preschoolers, even in safe and rural communities. Convenient neighbourhood PA facilities (eg, park and playground) might be positive in encouraging children's PA through parental support for participating in sports. For the development of interventions for young children, improvement in PA facilities in the neighbourhood, promoting parents' involvement should be taken into consideration. Future studies should investigate the association between both an objective inventory (eg, via systematic environmental audits) and measurements of the perception of the effect of the environment on activity outcomes, along with using a longitudinal study design to test the influence of environmental changes.

\section{Author affiliations}

${ }^{1}$ Department of Epidemiology, University Medical Centre Groningen, University of Groningen, Groningen, The Netherlands

${ }^{2}$ School of Public Health, Tianjin Medical University, Tianjin, China

${ }^{3}$ Tianjin Key Laboratory of Environment, Nutrition and Public Health, Centre for International Collaborative Research on Environment, Nutrition and Public Health, Tianjin, China

${ }^{4}$ Department of Nutrition and Food Science, School of Public Health, Tianjin Medical University, Tianjin, China

Correction notice This article has been corrected since it first published online. The open access licence type has been amended.

Acknowledgements The authors are grateful to the families who took part in the GECKO Drenthe study, to the midwives, gynaecologists, nurses and GPs for their help in the recruitment and measurement of participants and to the entire team of the GECKO Drenthe study.

Contributors EC designed the study and was involved in the interpretation of data and the discussion. $\mathrm{CL}$ analysed and interpreted the data, and drafted the manuscript. GH helped to interpret the data and revise the manuscript. All authors read and approved the final manuscript.

Funding This work was supported by an unrestricted grant from Hutchison Whampoa Ltd., Hong Kong, and by the University of Groningen, Well Baby Clinic Foundation Icare, Noordlease, Pediatric Association of the Netherlands and Youth Health Care Drenthe.

Disclaimer None sponsor was involved in the study design, data collection and analysis, interpretation of data, writing the manuscript and the decision to submit the paper for publication.

Competing interests None declared.

Patient consent for publication Obtained.

Ethics approval The study was approved by the Medical Ethics Committee of the University Medical Center Groningen and was performed in accordance with the Declaration of Helsinki.

Provenance and peer review Not commissioned; externally peer reviewed.

Data sharing statement The data sets used and analysed during the study are available from the corresponding author on reasonable request.

Open access This is an open access article distributed in accordance with the Creative Commons Attribution 4.0 Unported (CC BY 4.0) license, which permits others to copy, redistribute, remix, transform and build upon this work for any purpose, provided the original work is properly cited, a link to the licence is given, and indication of whether changes were made. See: https://creativecommons.org/ licenses/by/4.0/.

\section{REFERENCES}

1. Hallal PC, Andersen LB, Bull FC, et al. Global physical activity levels: surveillance progress, pitfalls, and prospects. Lancet 2012;380:247-57.

2. Goldfield GS, Harvey A, Grattan K, et al. Physical activity promotion in the preschool years: a critical period to intervene. Int J Environ Res Public Health 2012;9:1326-42.

3. Jones RA, Hinkley $T$, Okely AD, et al. Tracking physical activity and sedentary behavior in childhood: a systematic review. Am J Prev Med 2013;44:651-8.

4. Carson V, Lee EY, Hewitt L, et al. Systematic review of the relationships between physical activity and health indicators in the early years (0-4 years). BMC Public Health 2017;17:854,017-4860.

5. Geserick M, Vogel M, Gausche R, et al. Acceleration of BMI in early childhood and risk of sustained obesity. N Engl J Med 2018;379:1303-12

6. Carson V, Hunter S, Kuzik N, et al. Systematic review of sedentary behaviour and health indicators in school-aged children and youth: an update. Appl Physiol Nutr Metab 2016;41:S240-65.

7. Sallis JF, Cervero RB, Ascher W, et al. An ecological approach to creating active living communities. Annu Rev Public Health 2006;27:297-322.

8. Van Der Horst K, Paw MJ, Twisk JW, et al. A brief review on correlates of physical activity and sedentariness in youth. Med Sci Sports Exerc 2007;39:1241-50.

9. Edwardson CL, Gorely T. Parental influences on different types and intensities of physical activity in youth: a systematic review. Psychol Sport Exerc 2010;11:522-35.

10. Sijtsma A, Sauer PJ, Corpeleijn E. Parental correlations of physical activity and body mass index in young children--he GECKO Drenthe cohort. Int J Behav Nutr Phys Act 2015;12:132.

11. Määttä $S$, Ray $C$, Vepsäläinen $H$, et al. Parental education and preschool children's objectively measured sedentary time: the role of co-participation in physical activity. Int J Environ Res Public Health 2018;15:366.

12. Datar A, Nicosia N, Shier V. Parent perceptions of neighborhood safety and children's physical activity, sedentary behavior, and obesity: evidence from a national longitudinal study. Am J Epidemiol 2013;177:1065-73.

13. Larouche R, Garriguet D, Gunnell KE, et al. Outdoor time, physical activity, sedentary time, and health indicators at ages 7 to 14: 2012/2013 Canadian Health Measures Survey. Health Rep 2016;27:3-13.

14. Truelove S, Bruijns BA, Vanderloo LM, et al. Physical activity and sedentary time during childcare outdoor play sessions: a systematic review and meta-analysis. Prev Med 2018;108:74-85.

15. Okely $A D$, Ghersi $D$, Hesketh $K D$, et al. A collaborative approach to adopting/adapting guidelines - The Australian 24-Hour Movement Guidelines for the early years (Birth to 5 years): an integration of physical activity, sedentary behavior, and sleep. BMC Public Health 2017;17:869,017-4867.

16. Talarico R, Janssen I. Compositional associations of time spent in sleep, sedentary behavior and physical activity with obesity measures in children. Int $J$ Obes 2018;42:1508-14.

17. Chastin SF, Palarea-Albaladejo J, Dontje ML, et al. Combined effects of time spent in physical activity, sedentary behaviors and sleep on obesity and cardio-metabolic health markers: a novel compositional data analysis approach. PLoS One 2015;10:e0139984.

18. Panter JR, Jones AP, van Sluijs EM. Environmental determinants of active travel in youth: a review and framework for future research. Int $J$ Behav Nutr Phys Act 2008;5:34.

19. Tappe KA, Glanz K, Sallis JF, et al. Children's physical activity and parents' perception of the neighborhood environment: neighborhood impact on kids study. Int J Behav Nutr Phys Act 2013;10:39-10.

20. Carson V, Kuzik N, Hunter S, et al. Systematic review of sedentary behavior and cognitive development in early childhood. Prev Med 2015;78:115-22.

21. Kobes A, Kretschmer T, Timmerman G, et al. Interventions aimed at preventing and reducing overweight/obesity among children and adolescents: a meta-synthesis. Obes Rev 2018;19:1065-79.

22. Eichinger M, Schneider S, De Bock F. Subjectively and objectively assessed social and physical environmental correlates of 
preschoolers' accelerometer-based physical activity. Int J Behav Nutr Phys Act 2017;14:153.

23. Schmutz EA, Leeger-Aschmann CS, Radtke T, et al. Correlates of preschool children's objectively measured physical activity and sedentary behavior: a cross-sectional analysis of the SPLASHY study. Int J Behav Nutr Phys Act 2017;14:1.

24. Befort CA, Nazir N, Perri MG. Prevalence of obesity among adults from rural and urban areas of the United States: findings from NHANES (2005-2008). J Rural Health 2012;28:392-7.

25. Trivedi T, Liu J, Probst J, et al. Obesity and obesity-related behaviors among rural and urban adults in the USA. Rural Remote Health 2015;15:3267.

26. L'Abée C, Sauer PJ, Damen M, et al. Cohort Profile: the GECKO Drenthe study, overweight programming during early childhood. Int $J$ Epidemiol 2008;37:486-9.

27. Cole TJ, Lobstein T. Extended international (IOTF) body mass index cut-offs for thinness, overweight and obesity. Pediatr Obes 2012;7:284-94

28. Aarts MJ, de Vries SI, van Oers HA, et al. Outdoor play among children in relation to neighborhood characteristics: a crosssectional neighborhood observation study. Int J Behav Nutr Phys Act 2012;9:98.

29. Aarts MJ, Wendel-Vos W, van Oers HA, et al. Environmental determinants of outdoor play in children: a large-scale crosssectional study. Am J Prev Med 2010;39:212-9.

30. Brouwer SI, Küpers LK, Kors L, et al. Parental physical activity is associated with objectively measured physical activity in young children in a sex-specific manner: the GECKO Drenthe cohort. BMC Public Health 2018;18:1033.

31. Aadland E, Johannessen K. Agreement of objectively measured physical activity and sedentary time in preschool children. Prev Med Rep 2015;2:635-9.

32. Butte NF, Wong WW, Lee JS, et al. Prediction of energy expenditure and physical activity in preschoolers. Med Sci Sports Exerc 2014;46:1216-26.

33. Choi L, Liu Z, Matthews CE, et al. Validation of accelerometer wear and nonwear time classification algorithm. Med Sci Sports Exerc 2011;43:357-64.
34. Davison KK, Lawson CT. Do attributes in the physical environment influence children's physical activity? A review of the literature. Int $J$ Behav Nutr Phys Act 2006;3:19.

35. Frost SS, Goins RT, Hunter RH, et al. Effects of the built environment on physical activity of adults living in rural settings. Am J Health Promot 2010;24:267-83.

36. Loprinzi PD, Trost SG. Parental influences on physical activity behavior in preschool children. Prev Med 2010;50:129-33.

37. Stokols D. Translating social ecological theory into guidelines for community health promotion. Am J Health Promot 1996;10:282-98

38. Aarts MJ, Mathijssen JJ, van Oers JA, et al. Associations between environmental characteristics and active commuting to school among children: a cross-sectional study. Int J Behav Med 2013;20:538-55.

39. Ding D, Sallis JF, Kerr J, et al. Neighborhood environment and physical activity among youth a review. Am J Prev Med 2011;41:442-55.

40. McCurdy LE, Winterbottom KE, Mehta SS, et al. Using nature and outdoor activity to improve children's health. Curr Probl Pediatr Adolesc Health Care 2010;40:102-17.

41. Bassett DR, John D, Conger SA, et al. Trends in physical activity and sedentary behaviors of United States Youth. J Phys Act Health 2015;12:1102-11.

42. Russ SA, Larson K, Franke TM, et al. Associations between media use and health in US children. Acad Pediatr 2009;9:300-6.

43. Füzéki E, Engeroff T, Banzer W. Health benefits of light-intensity physical activity: a systematic review of accelerometer data of the National Health and Nutrition Examination Survey (NHANES). Sports Med 2017;47:1769-93.

44. Pfeiffer KA, Dowda M, Mclver KL, et al. Factors related to objectively measured physical activity in preschool children. Pediatr Exerc Sci 2009;21:196-208.

45. Oliver M, Schofield GM, Schluter PJ. Parent influences on preschoolers' objectively assessed physical activity. J Sci Med Sport 2010;13:403-9. 